\title{
Classifying the Disciplinarity of Engineering Academic Literature
}

\author{
Susan LATTANZIO a,1, Nataliya MOGLES ${ }^{\text {a }}$, Emily CAREY ${ }^{\mathrm{a}}$, Alex KHARLAMOV ${ }^{\mathrm{b}}$, \\ Glenn PARRY ${ }^{\mathrm{b}}$, Ben HICKS ${ }^{\mathrm{c}}$ and Linda NEWNES ${ }^{\mathrm{a}}$ \\ ${ }^{a}$ The University of Bath, Bath, UK \\ ${ }^{\mathrm{b}}$ The University of Surrey, Guildford, UK \\ ${ }^{\mathrm{c}}$ The University of Bristol, UK
}

\begin{abstract}
Based on the appearance of the term within the academic literature, it would appear that transdisciplinarity (TD) approaches are receiving increased research attention. However, the literature suggests a lack of consensus over how TD is defined and classified. This could give rise to inconsistency and papers that claim to be TD which are not, and alternatively papers that fail to mention TD but which might be classified as such. This is significant and creates a challenge in identifying the true level of TD research. This work contributes towards understanding the state of TD within engineering. Explicitly, we address the research question: Is the engineering academic literature claiming to be $\mathrm{TD}$, actually TD? Within this study we operationalise the work of Jantsch and use this as a means to classify the disciplinarity of 177 engineering journal papers which reference TD within their abstract. The results show only $24 \%$ to be TD. The majority (64\%) are classified as interdisciplinary. Conclusions find that to improve consistency, a clear definition and rules for differentiation between TD and ID research are required. Future work calls for: (1) comparative studies which apply different methods for assessing disciplinarity across the dataset used within this study and which use the method employed within this study across different fields. (2) Research to analyse whether TD working is being undertaken in engineering without it being referenced within the paper.
\end{abstract}

Keywords. Transdisciplinary, Trans-disciplinarity, Disciplinarity, Transdisciplinary Engineering, Content Analysis.

\section{Introduction}

Contemporary engineering products and systems are getting evermore interconnected with multiple disciplines and stakeholders involved in all aspects of the lifecycle $[1,2]$. This complexity necessitates a need to move away from a traditional reductionist discipline-based approach, to go above and beyond the disciplinary boundaries. That is, there is a need for transdisciplinary engineering (TE) approaches. However, despite engineering being a designated field for transdisciplinarity (TD) a recent study suggests that compared to interdisciplinary (ID) and multidisciplinary (MD) approaches, the penetration of TD is low [3].

Although providing a view of the use of TD within engineering, the work of Lattanzio, Carey [3] presents a certain perspective. That is, the analysis uses the appearance of the terms MD, ID, TD within the engineering papers. It does not look to further examine whether the papers conform to any particular definition of these terms.

\footnotetext{
${ }^{1}$ Corresponding Author, Mail: S.Lattanzio@bath.ac.uk
} 
One of challenges with understanding the use of TD within engineering is the loose way the term is used. Broadly, TD has been defined as 'a research approach that includes multiple scientific disciplines (interdisciplinarity) focusing on shared problems and the active input of practitioners from outside academia' [4]. However, both across and within the different academic fields a plurality of definitions of TD persist [5]. This has resulted in a situation whereby what one author considers TD might be considered a different level of disciplinary by another [5]. Adding to this challenge is that funders are starting to call for research to be using a TD approach [6]. Potentially, this inconsistency in definition, coupled with the evolving "fashion" for TD work, could result in a situation whereby research claiming to be TD does not meet all, or indeed, any of the existing definitions of the term.

This study aims to contribute towards understanding the state of TD within engineering academic research by answering the research question: Is the engineering academic literature claiming to be TD, actually TD?

The paper is structured as follows: First, the background literature. Within this section the seminal work of Jantsch [7] which provides the underpinning theoretical framework for this study is introduced (Section 1). Following, the research approach is described in detail (Section 2). The approach involves the creation of a coding agenda which can be used to classify research disciplinarity. This coding agenda is applied to the academic engineering literature which references TD within the abstract. The results are presented (Section 3), and discussed (Section 4). Finally, conclusions are formulated (Section 5), limitations identified (Section 6) and future research work recommended (Section 7).

\section{Background}

It is generally accepted that the origins of TD date back to the 1970s and the original work of Jantsch [7]. Within this work Jantsch asserts that for education and innovation to be of value to society it needs to cut across the social, economic, political, technological, psychological, anthropological and other dimensions. Using a holistic approach, Jantsch defines a hierarchical framework that identifies key levels for consideration within a multi-level, multi-goal education and innovation system (Figure $1)$.

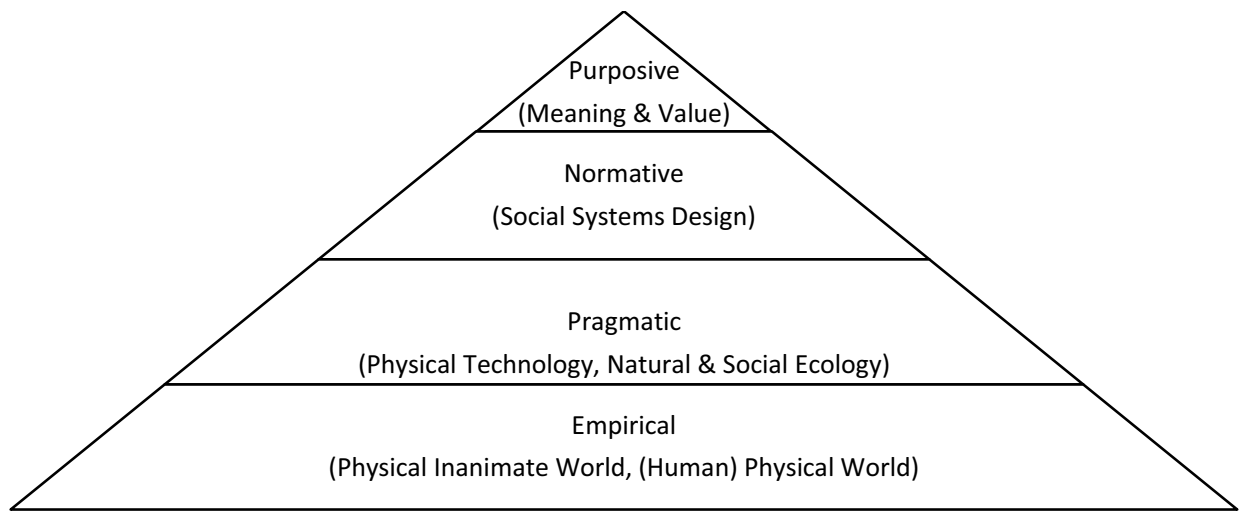

Figure 1. Adapted version of Jantsch's education/innovation system [7]. 
Building on this framework, Jantsch defined six disciplinarity levels: monodisciplinarity, multidisciplinarity, pluridisciplinarity, crossdisciplinarity, interdisciplinarity, and transdisciplinarity. These definitions are constructed based on differences in cooperation and coordination within and across the purposive, normative, pragmatic and empirical levels.

Although the creator of the original framework, Jantsch's conceptualisation has not been universally accepted. To-date, there are a pluality of approaches proposed to differentiate between disciplinary levels [8-12]. The inconsistency is compounded by the evolution from simple, abstract categorisations, to typologies which acknowledge the nuances and complexity within each of the disciplinary states [13]. As an example, Bruun, Hukkinen [14] subdivide multi- and interdisciplinarity into encyclopedic MD, contextualizing MD, composite MD, empirical ID, methodological ID, theoretical ID. The lack of consensus would suggest that although papers may claim to be TD, their classification is dependent upon the definition applied.

Whilst a number of conceptual approaches for assessing disciplinarity exist there have been few attempts to apply these to characterise the disciplinarity of research efforts, and thus there is no universally accepted approach to classifying the disciplinarity of academic engineering literature [13]. Within this work we address this gap by operationalising the work of Jantsch, creating a coding agenda and applying it to academic engineering literature.

\section{Research approach}

The aim of this study was to contribute to understanding how TD approaches are being used within engineering academic research. This research assesses the disciplinary level of engineering academic literature which appears to be TD, to see if it meets the definition of TD as proposed by Jantsch. The approach used within this research is illustrated by Figure 2 .

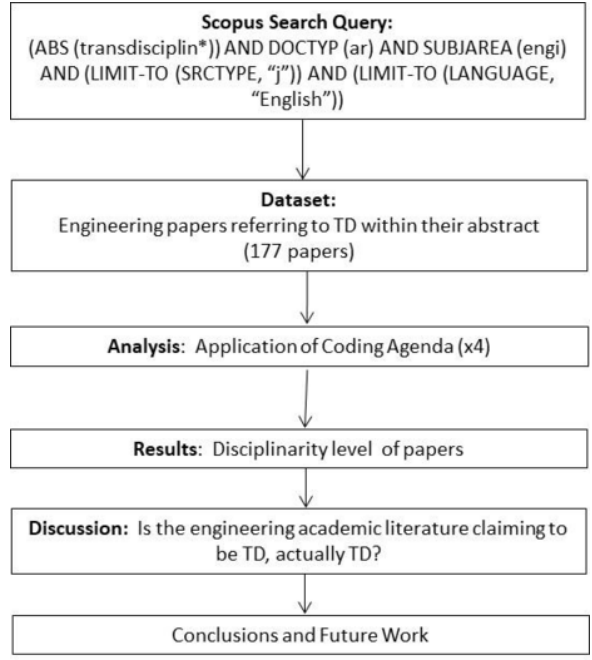

Figure 2. Research approach. 
The dataset used within this study was extracted from Scopus. Scopus was considered preferential to Web of Science as it provided $20 \%$ more coverage and incorporated a wider range of journals [15]. The dataset was limited to papers which Scopus identified as falling with the engineering subject area, with the term "transdiscipl*" within the abstract. This is used as a proxy for work claiming to be TD. The search uses the wildcard "*" to capture any possible ending of this term e.g. transdiscipline, transdisciplinary, transdisciplinarity. To ensure a level of quality the search was constrained to peer-reviewed journal articles, and for accessibility those written in English. Applying this search 177 papers were returned.

A coding agenda (described in Section 2.1), was used to analyse the abstracts and assess their level of disciplinarity.

\subsection{Coding Agenda}

Key to understand the extent that TD approaches are being used within engineering academic research is having a consistent way to classify disciplinarity. To achieve this a coding agenda was created which operationalised the work of Jantsch [7, 16]. The rationale for using Jantsch is that to date there is no consensus on how to classify disciplinarity. An originator of the field, the work of Jantsch provides a framework which can be operationalised into an approach which is both complete and practical.

A coding agenda contains the rules which are used to apply a classification. To create a coding agenda, artefacts (i.e. documents, audio recordings, video) are anlaysed. A wide range of theoretical frameworks and techniques have been proposed to undertake content analysis [17-20]. Within this work we follow the steps defined by Mayring [19]. The rationale for this choice is that the steps offer a structured and repeatable process (Figure 3).

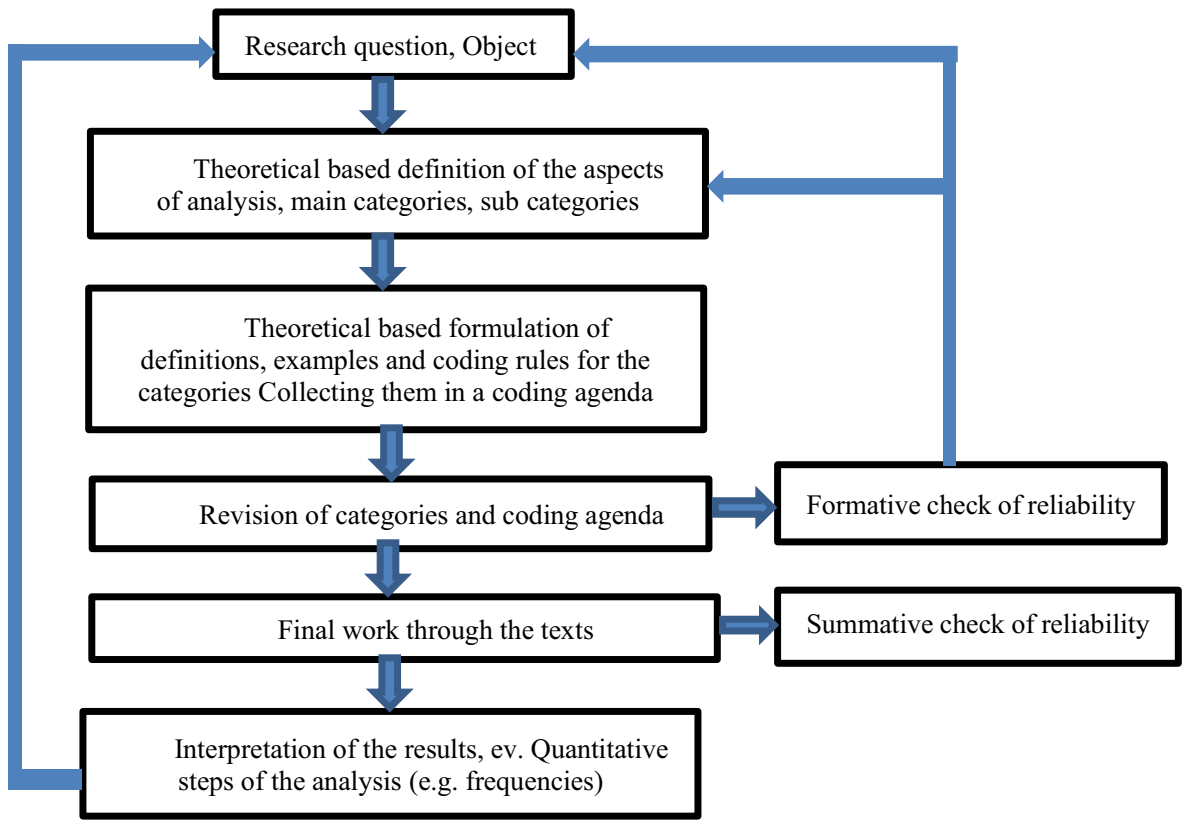

Figure 3. Step model of deductive category application. Adapted from Mayring [19]. 
The outputs of the content analysis informed the creation of the disciplinary coding agenda presented in Table 1.

Table 1. Disciplinary coding agenda.

\begin{tabular}{|c|c|c|}
\hline Category & Definition of Jantsch & Coding rules \\
\hline $\begin{array}{l}\text { Monodisciplinary } \\
\text { (M) }\end{array}$ & $\begin{array}{l}\text { Specialisation in isolation. } \\
\text { One-level, single-goal; no co- } \\
\text { operation. }\end{array}$ & $\begin{array}{l}\text { Research related to one level of Jantsch's } \\
\text { framework - one discipline. No involvement of } \\
\text { practical engineers. No reference to a broader } \\
\text { research application scope and relation to other } \\
\text { disciplines. No reference to stakeholders at the } \\
\text { normative level. }\end{array}$ \\
\hline $\begin{array}{l}\text { Multi, Pluri, } \\
\text { Crossdisciplinary } \\
\left(\mathrm{MD}^{*}\right)\end{array}$ & $\begin{array}{l}\text { No cooperation; cooperation } \\
\text { without coordination; rigid } \\
\text { polarisation towards specific } \\
\text { mondisciplinary concept. } \\
\text { One-level, multi-goal, } \\
\text { cooperation (but no } \\
\text { coordination) }\end{array}$ & $\begin{array}{l}\text { Combines approaches from different } \\
\text { disciplines, but no specific indication of a } \\
\text { coordination by a higher-level concept. }\end{array}$ \\
\hline $\begin{array}{l}\text { Interdisciplinary } \\
\text { (ID) }\end{array}$ & $\begin{array}{l}\text { Coordination by higher level } \\
\text { concept. } \\
\text { Two-level, multi-goal; } \\
\text { coordination from a higher } \\
\text { level. }\end{array}$ & $\begin{array}{l}\text { At least two levels of Jantsch's framework are } \\
\text { involved. Methods and approaches of at least } \\
\text { two disciplines are mentioned in the abstract } \\
\text { and the disciplines' approaches are coordinated } \\
\text { by higher-level research or innovation concept. }\end{array}$ \\
\hline $\begin{array}{l}\text { Transdisciplinary } \\
\text { (TD) }\end{array}$ & $\begin{array}{l}\text { Multilevel coordination of } \\
\text { entire education/innovation } \\
\text { system. } \\
\text { Multi-level multi-goal; } \\
\text { coordination toward a common } \\
\text { system purpose. }\end{array}$ & $\begin{array}{l}\text { All four levels of Jantsch's research and } \\
\text { innovation system should be present: Explict } \\
\text { consideration of societal meaning and value. } \\
\text { Collaboration with stakeholders at the } \\
\text { normative level. Involvement of more than one } \\
\text { discipline at the pragmatic/empirical levels. }\end{array}$ \\
\hline
\end{tabular}

(*) Within this paper we use Multi* to denote that for our coding Multi* encompasses Pluri-, Cross- and multidisciplinarity.

The coding agenda contains three columns: Category, Definition of Jantsch, Coding rules. The Category is the classification which is applied within the analysis. It should be noted that within this paper we have used the term Multi* $\left(\mathrm{MD}^{*}\right)$ to encompass pluri-, cross- and multidisciplinary papers. This approach was used because the nuances that separate the three terms would be difficult to identify from an abstract, and provide a level of detail which is not required to address the research question. The second column provides the definitions of Jantsch taken from the original works [7, 16]. Finally, the third column details the coding rules against which classifications are made.

When conducting the analysis the coding agenda was applied to each abstract within the dataset. Within the literature a number of ways have been suggested to improve the reliability of coding. These include increasing the numbers of individuals coding the data, choosing coders familiar with the constructs to be identified, and training coders in systematic practice sessions $[13,21]$. Within this work two strategies were adopted: 1 . Coding was undertaken by four Research Associates with previous exposure to the work of Jantsch. The eventual classification made was the mode of the four responses. If no 
mode arose from the coded abstracts the coders were given the opportunity to first discuss, and where they considered appropriate, adjust their individual response. Through this means consensus was achieved. 2. Prior to commencing coding a training set of 50 papers was used as a means through which to improve coder calibaration.

\section{Results ${ }^{2}$}

Though no time period was set, analysis of the 177 papers within the dataset showed them to have been produced over the period $1980-2018$, with accelerated growth seen from 2000 onwards (Figure 4). This supports that over recent years a greater number of engineering journal papers are using the term TD.

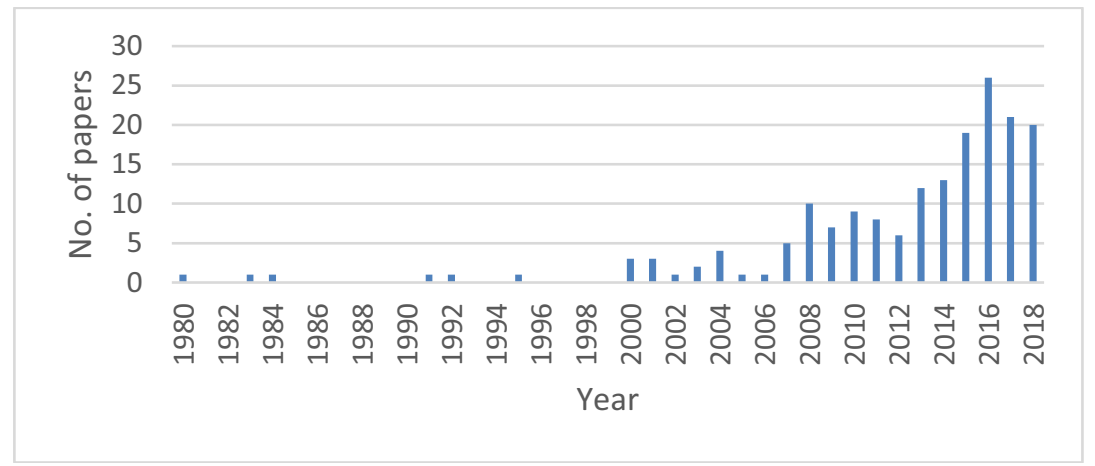

Figure 4. Engineering papers with "Transdisciplin*" with their abstract, extracted from Scopus 25/3/2019.

Of the 177 , three papers were excluded because they were not research contributions, but rather informal essays or publication volume descriptions. The coding agenda was applied to the remaining 174 abstracts in order to analyse their level of disciplinarity.

The results of the analysis are presented in Figure 5. This shows that of the 174 papers less than a quarter (24\%) meet the definition of TD. A total of 111 of the abstracts are classified as ID (64\%), with $11 \%$ classified as MD*. No papers were categorised as monodisciplinary $(\mathrm{M})$.

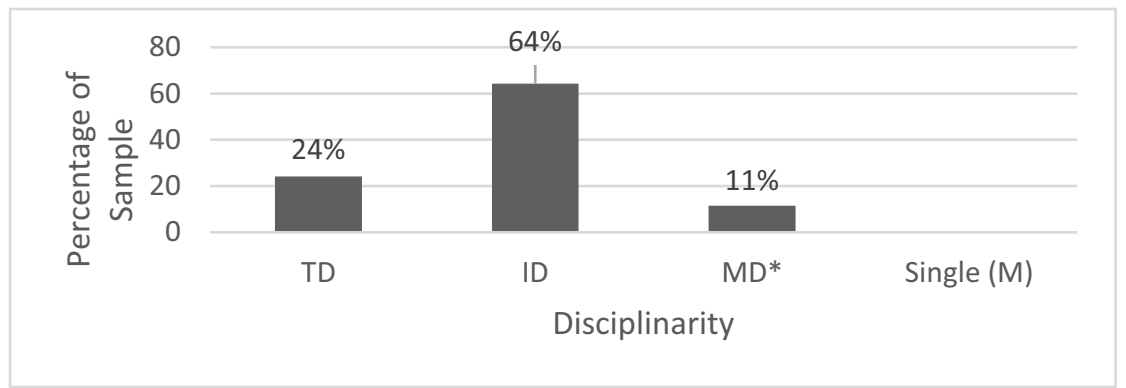

Figure 5. Classification of engineering academic literature by disciplinarity.

\footnotetext{
${ }^{2}$ The complete results dataset can be accessed at https://researchportal.bath.ac.uk/.
} 


\section{Discussion \& Conclusions}

Since the year 2000 a greater number of engineering journal papers have referenced TD (Figure 4). Although showing an increase in numbers, this does not necessarily mean there has been an increase in the overall percentage of TD papers relative to total publications. To test this, further analysis to normalise the data against the increase in engineering papers overall, is required.

The results of the classification (Figure 5) show that although papers might claim to be TD, when applying the coding agenda based on the work of Jantsch, only $24 \%$ met the definition. The majority (64\%) would be more accurately defined as ID. Less papers $(11 \%)$ were classified as multi*- and none as mono. This would suggest that a greater challenge lies in differentiating TD from ID, rather than from MD* or M.

The reasons behind the TD / ID coding differences are not known, but could be both unintentional or intentional. Unintentional rationales might look towards the plurality of disciplinary frameworks. In this regard, the authors may not have conducted research which is TD according to Jantsch, but which might meet alternative definitions. Intentional rationales might look towards the current trend towards TD which may encourage research to be framed as TD in order to meet funder requirements or to appear novel.

When attempting to understand a problem such as this it is useful to be able to triangulate findings against other studies. Comparison of these results to other studies is challenging. First, there have been very few serious attempts to categorise the disciplinary state of research [13] and as far as we are aware, none which have looked to assess whether work claiming to be TD meets that definition. Second, the plurality of definitions means that for the studies which do exist, different approaches may have been used. For example, based on the literature and their own experiences during the empirical analysis, Huutoniemi, Klein [13] create a new disciplinary typology. This is used to assess 266 research project proposals funded by the Academy of Finland. They find $\sim 40 \%$ (106 projects) to be ID, which is less than our finding of $64 \%$ ID. However, crosscomparison of the two results is challenging as not only do the authors use a different approach for classifying disciplinarity, they use different sampling criteria looking at any research proposals from 1997 and 2000. This is in contrast to our dataset which looked at any TD papers and returned papers from 1980-2018. That is, our dataset contained papers produced nearly two decades later.

Similarly, recent analysis by Van Noorden [22] finds $\sim 35 \%$ of Natural Sciences and Engineering and $\sim 50 \%$ of Social Sciences publications to be ID. Again, this employs a different method of analysis in which 35 million papers from the Web of Science are automatically classified.

\section{Conclusions}

Within this study we seek to understand whether engineering papers claiming to be TD, are actually TD. Our results showed that only around a quarter $(\sim 24 \%)$ of papers referencing TD within their abstract, meet the definition of TD found in the original classification work of Jantsch. The majority (64\%) were classified as ID. These findings 
highlight that within the academic engineering literature there is still much inconsistency in what might be reported as TD and points to the importance of establishing clearer disciplinary definitions and established rules which differentiate TD from ID.

\section{Limitations}

Currently, it is not a requirement for the author to state the level of disciplinarity of their work. Within this work we use the appearance of the term within the abstract as a proxy for work claiming to be TD. It is recognised that some papers may not be making this claim. Furthermore, within this study classification of disciplinarity is based on analysis of the abstract. Although it is expected that within an academic paper the abstract would represent fully the research undertaken, this is not always the case. Constraining the sample to journal papers appearing on Scopus (and therefore respected sources), mitigates this risk.

\section{Future work}

The research within this paper seeks to address whether engineering papers which claim to be TD, are indeed TD. During this work we operationalise the work of Jantsch and use this to create a means to classify disciplinarity. Although adding to the understanding, for a more complete picture future research is required:

1. Investigations of possible overlaps between the TD, ID, and MD literature. Research in this area has commenced. A study conducted within the TREND group has analysed $\mathrm{N}$-grams and Bi-grams taken from the abstracts of 8834 papers to ascertain commonalities or differences between disciplinarities. The results of this study are presented as separate paper [23].

2. Undertake research which allows the results of this work to be triangulated. In this regards, studies should look to apply alternative disciplinarity typologies to the same dataset used within this work, or apply the method used within this study to different academic fields.

3. This work looks to identify whether engineering academic literature claiming to be TD is TD. The alternative question is whether there is work which is not identified as TD, but which meets the definition.

\section{Acknowledgement}

The work reported in this paper was undertaken as part of the Designing the Future: Resilient Trans-Disciplinary Design Engineers Project, at the Universities of Bath, Bristol and Surrey. The project is funded by the Engineering and Physical Sciences Research Council (EPSRC) Grant EP/R013179/1. 


\section{References}

[1] N. Wognum, C. Bil, F. Elgh, M. Peruzzini, J. Stjepandic and W.J.C. Verhagen, Transdisciplinary engineering research challenges, Advances in Transdisciplinary Engineering, Vol. 7, 2018, pp. 753-762.

[2] N. Wognum, C. Bil, F. Elgh, M. Peruzzini, J. Stjepandic and W.J.C. Verhagen, Transdisciplinary systems engineering: implications, challenges and research agenda, International Journal of Agile Systems and Management, Vol. 12, 2019, pp. 58-89.

[3] S. Lattanzio, E. Carey, A. Hultin, R. Imani Asrai, M. McManus, N. Mogles, G. Parry and L.B. Newnes, Transdisciplinarity Within the Academic Engineering Literature, International Journal of Agile Systems and Management, 2020, Vol. 13, No. 2, pp. 213-232.

[4] P. Brandt, E. Anna, F. Gralla, C. Luederitz, D.J. Lang, J. Newig, F, Reinert, D. Abson and H. Von Wehrden, A review of transdisciplinary research in sustainability science, Ecological Economics, Vol. 92, 2013. pp. 1-15.

[5] C. Pohl, C and G.H. Hadorn, Principles for Desigining Transdisciplinary Research, Swiss Academies of Arts and Sciences, Bern, 2007.

[6] UKRI, 2019, Future Manufacturing Systems, Accessed: 21102019. [Online]. Available: https://epsrc.ukri.org/funding/calls/future-manufacturing-systems/.

[7] E. Jantsch, Inter- and transdisciplinary University: A Systems Approach to Education and Innovation, Policy Sciences, Vol 1, 1970, pp. 7-37.

[8] A. Bruce, C. Lyall, J. Tait, R. Williams, Interdisciplinary Integration in Europe: The Case of the Fifth Framework Programme, Futures, 2004, Vol. 36, pp. 457-470.

[9] J.J. Kockelmans, Why interdisciplinarity? Interdisciplinarity and Higher Education, The Pennsylvania State University Press, University Park and London, 1979.

[10] R.J. Lawrence, Housing and Health: From Interdisciplinary Principles to Transdisciplinary Research and Practice, Futures, Vol. 36, 2004, pp. 487-502.

[11] T. Ramadier, Transdisciplinarity and its Challenges: The Case of Urban Studies, Futures, Vol. 36, 2004, pp. 423-439.

[12] B.R. Tress and G. Fry, From Landscape Research to Landscape Planning - aspects of integration, education and application, Defining concepts and the process of knowledge production in integrative research, Wageningen UR Frontis Series 12, 2006.

[13] K. Huutoniemi, J. Thompson Klein, H, Bruun, J. Janne, Analyzing interdisciplinarity: Typology and indicators, Research Policy, Vol. 39, 2010. pp. 79-88.

[14] H. Bruun, J.I. Hukkinen, K.I. Huutoniemi, J.Thompson Klein, Promoting Interdisciplinary research. The Case of the Academy of Finland 2005, The Academy of Finland, Helsinki, 2005.

[15] A, Aghaei Chadegani, H. Salehi, M. Yunus, H. Farhadi, M. Fooladi, M. Farhadi and N. Ale Ebrahim 2013, A Comparison between Two Main Academic Literature Collections: Web of Science and Scopus Databases, IDEAS Working Paper Series from RePEc, IDEAS Working Paper Series from RePEc, 2013.

[16] CERI, Interdisciplinarity: Problems of teaching and research in Universities, 1972.

[17] K. Bailey, Methods of social research, Simon and Schuster, 2008.

[18] N.K. Denzin and Y.S. Lincoln, Handbook of qualitative research, Sage Publications, Thousand Oaks, CA, 1994.

[19] P. Mayring, Qualitative content analysis: theoretical foundation, basic procedures and software solution. 2014. Available from: https://nbn-resolving.org/urn:nbn:de:0168-ssoar-395173.

[20] M.B. Miles and A.M. Huberman, Qualitative data analysis: An expanded sourcebook, Sage Publications, Thousand Oaks, CA, 1994.

[21] D. Atkinson and M. Murray, Improving Interrater Reliability, in Annual Meeting of the Conference on College Composition and Communication, Atlanta, GA, 1987.

[22] R. Van Noorden, Interdisciplinary research by the numbers, Nature, Vol. 525, 2015, pp. 306-307.

[23] E. Carey, J. Gopsil and L. Newnes, Text Analysis of Disciplinary Research Papers, in The 27th Transdisciplinary Engineering Conference, Warsaw, Poland, 2020. 